\title{
AVALIAÇÃO EM CURSOS SUPERIORES DE ARTES: A ÊNFASE NO PROCESSO E A EDUCAÇÃO PELO SENSÍVEL
}

\author{
EVALUATION IN ARTS HIGHER EDUCATION: \\ THE EMPHASIS ON THE PROCESS AND THE EDUCATION BY THE \\ SENSITIVE
}

\author{
Josélia Schwanka Salomé \\ Doutora em Artes pela Unicamp \\ Professora Adjunta da Universidade Tuiuti do Paraná (UTP) \\ joselia.salome@utp.br \\ iD Maria Cristina Mendes \\ Doutora em Comunicação pela Universidade Tuiuti do Paraná (UTP) \\ Professora Adjunta da Universidade Estadual de Ponta Grossa (UEPG) e na FAP/ UNESPAR \\ mariacristinamendes1@gmail.com
}

\begin{abstract}
Resumo: O artigo trata da problemática advinda da subjetividade inerente às avaliações realizadas nos ateliês dos cursos de arte do ensino superior. Busca-se contribuir para as pesquisas da área por meio da identificação de possíveis caminhos que conduzam à adoção de critérios que possibilitem o equilíbrio entre aquisição de conhecimento e educação pelo sensível. Parte-se de uma abordagem do ensino como um todo, no afã de incluir os cursos responsáveis pela habilitação de professores para o Ensino Fundamental; Descartes, Morin, Libâneo e Luckesi embasam esta parte introdutória. No que concerne à avaliação no ensino superior, destaca-se a necessidade de uma educação integral, voltada para o incentivo da pesquisa e pautada na relação entre especificidades da área e equilíbrio afetivo/ emocional; Masseto, Vieira e De Sordi norteiam este segmento da investigação. No tópico que trata da avaliação nos cursos de artes, é pontuada a presença do artista-professor e a ênfase atribuída ao aspecto processual da avaliação; com Garcia, Feyerabend, Tourinho e Almeida valorizam-se o processo de construção do conhecimento e o olhar sensível para a produção do estudante. Enfatiza-se, ao longo do texto, a necessidade de transformação dos moldes avaliativos tradicionais. Observa-se, na pesquisa sobre avaliação em cursos superiores de arte, que é necessária a atenção tanto no processo quanto no produto final, e que a avaliação seja concebida a partir de critérios que coadunem questões subjetivas e objetivas.
\end{abstract}

Palavras-chave: Ensino superior. Avaliação em artes. Práticas pedagógicas.

\begin{abstract}
The article deals with the problem arising from the subjectivity inherent to the evaluations carried out in the ateliers of higher education art courses. It seeks to contribute to research in the area by identifying possible paths that lead to the adoption of criteria that enable the balance between knowledge acquisition and education by the sensitive. It is based on an approach of teaching as a whole, in the desire to include courses that are responsible for the qualification of teachers for elementary education; Descartes, Morin, Libâneo and Luckesi support this introductory part. With regard to evaluation in higher education, the need for integral education is highlighted, focused on encouraging research and based on the relationship between specificities of the area and affective / emotional balance; Masseto, Vieira and De Sordi guide this segment of the investigation. In the topic that deals with evaluation in the art courses, the presence of the artist-teacher and the emphasis given to the procedural aspect of the evaluation are highlighted; with Garcia, Feyerabend, Tourinho and Almeida, the process of knowledge construction and the sensitive view of the student's production are valued. Throughout the text, the need to transform traditional assessment models is emphasized. It is observed, in this research on evaluation in higher art courses, that attention is needed both in the process and in the final product, and that evaluation is conceived upon criteria that match subjective and objective issues.
\end{abstract}

Keywords: Higher education. Arts assessment. Pedagogical practices.

Para citar - (ABNT NBR 6023:2018)

SALOMÉ, Josélia Schwanka; MENDES, Maria Cristina. Avaliação em cursos superiores de artes: a ênfase no processo e a educação pelo sensível. Eccos - Revista Cientifica, São Paulo, n. 55, p. 1-11, e18872, out./dez. 2020. Disponível em: https://doi.org/10.5585/eccos.n55.18872. 
O lugar da arte na educação universitária dependerá do reconhecimento a ela atribuído no currículo normal $[\ldots]$

Herbert Read

\title{
1 Avaliação: o bom senso e a lucidez antropoética
}

Critérios de avaliação compõem um intrincado enigma tanto para quem avalia quanto para quem é avaliado, e por mais que se tente comprovar a objetividade do processo avaliativo esbarra-se em questões de cunho filosófico inextrincável. Se for levado em conta que boa parte dos julgamentos de valor praticados cotidianamente não se ancora na concretude dos fatos, mas em percepções subjetivadas, é importante, retomar as palavras do criador do método cartesiano, cuja contribuição para a metodologia de análise e avaliação das coisas do mundo está longe de ter se esgotado. De acordo com René Descartes:

\begin{abstract}
O bom senso é a coisa mais bem distribuída no mundo: pois cada um pensa estar tão bem provido dele, que mesmo aqueles mais difíceis de se satisfazerem com qualquer outra coisa não costumam desejar mais bom senso do que têm. Assim, não é verossímil que todos se enganem; mas, pelo contrário, isso demonstra que o poder de bem julgar e de distinguir o verdadeiro do falso, que é propriamente o que se denomina bom senso ou razão, é por natureza igual em todos os homens; e, portanto, que a diversidade de nossas opiniões não decorre de uns serem mais razoáveis que os outros, mas somente de que conduzimos nossos pensamentos por diversas vias, e não consideramos as mesmas coisas. Pois não basta ter o espírito bom, mas o principal é aplicá-lo bem. (DESCARTES, 2011, p. 5).
\end{abstract}

As opções de escolha e de valoração adotadas ao longo de um simples dia explicitam a diversidade do mundo; e muitas vezes, a esperança de que as certezas advindas da opinião pessoal possam ser compartilhadas costumam cair por terra. Tais dificuldades para se atribuir valor, certamente, não poderiam deixar de estar presentes em outros tipos de avaliação, dentre as quais podem ser incluídas as avaliações realizadas nos processos de ensino e aprendizagem.

As definições de educação, contudo, têm sofrido substanciais alterações nas últimas décadas e é relevante pontuar quais os objetivos educacionais que se propõem para pensar possíveis formas de avaliação. De acordo com Edgar Morin (2011), ao estabelecer parâmetros para a educação do futuro, é importante lembrar que a tríade indivíduo, sociedade e espécie é um sistema complexo, cuja interação resulta na cultura. Ao destacar o valor da consciência nos processos educacionais, o filósofo destaca a presença de uma antropoética, conceito com bases em uma ética humanista, cujo objetivo é possibilitar o bom convívio entre as pessoas.

De acordo com a antropoética moriniana, dentre os objetivos da educação destaca-se o trabalho de humanização da humanidade, o respeito pelas diferenças individuais e o desenvolvimento da solidariedade e da compreensão. Segundo o estudioso da cultura e da educação, para uma formação que tenha consciência da complexidade do caráter globalizado 
da humanidade, é necessário romper com as barreiras criadas pela compartimentação disciplinar, responsável por afastar a humanidade de sua integridade. Para Morin (2011, p. 31): “o dever principal da educação é de armar cada um para o combate vital para a lucidez".

A complexa trama educacional que permeia a vida dos indivíduos nas diversas etapas de sua formação necessita de mudanças que, vinculadas às transformações sócio-culturais, produza conhecimento para o exercício da cidadania. A formação individual, diante das incertezas do conhecimento, tece possibilidades cognitivas e sensíveis que possibilitam o estabelecimento de relações dialógicas entre diversas partes do todo. Questões que envolvem a educação e a vida concreta não podem deixar de levar em conta os aspectos éticos envolvidos no processo de avaliação do ensino e da aprendizagem.

Correlacionar cotidianidades e conceitos científicos são atributos da educação formal, cujo período de atuação engloba todo o percurso escolar. O problema que se apresenta, de saída, são as diferentes experiências individuais, as quais, em prol do nivelamento do grupo de estudantes, deixam muitas vezes de ser levadas em conta. Ao considerar singularidades dos alunos no processo de ensino e aprendizagem, o aprofundamento nas questões particulares conduz a um melhor aproveitamento dos conteúdos selecionados, pois correlaciona o mundo concreto e a vida do estudante.

Tradicionalmente, a educação é pautada em aulas expositivas, nas quais o professor é o maior responsável pelo aprendizado dos estudantes. As avaliações, grosso modo, são realizadas por meio de provas escritas e/ ou orais, cujo intuito é mensurar a aquisição do conhecimento prático e teórico, em tentativas de quantificar os resultados obtidos. Tal modelo educacional deixa em aberto questões éticas fundamentais, pois o excesso de verticalização da relação professor/ aluno permite que injustiças possam ser mais facilmente validadas. Se o modelo tradicional já não mais corresponde às necessidades advindas das substantivas alterações sociais, cabe ao educador investigar e desenvolver outros métodos de avaliação, mais adequados à atualidade.

No âmbito da avaliação escolar, José Carlos Libâneo lembra que o avaliar envolve a objetividade e a subjetividade tanto do professor quanto do aluno e destaca a importância de uma avaliação equilibrada:

Se somente levar em conta aspectos objetivos, [a avaliação] acaba tornando-se mecânica e imparcial; atendo-se somente às necessidades e condições internas dos alunos, pode comprometer o cumprimento das exigências sociais requeridas da escola. (LIBÂNEO, 2006, p. 203). 
Contrabalançar questões objetivas e aspectos subjetivos é uma das tarefas do educador, que se vê diante da necessidade de mensurar o crescimento cognitivo, intelectual e humanista do estudante. De acordo com o educador, a avaliação propicia reflexões acerca do conjunto de objetivos, conteúdos e métodos adotados, permite a revisão do plano de ensino e auxilia no desenvolvimento de capacidades e habilidades. Ao se voltar para a atividade estudantil, deve ser objetiva, auxiliar na autopercepção do professor e refletir valores e expectativas do mesmo em relação aos estudantes. A nota ou o conceito atribuído ao aluno, longe de ser o objetivo do ensino, apenas explicita níveis de aproveitamento em relação aos objetivos propostos (LIBÂNEO, 2006).

Para Cipriano Carlos Luckesi, a avaliação é um ato amoroso, cuja prática acontece diante de uma sociedade que não é amorosa e faz com que a avaliação escolar e a vida em sociedade pareçam traçar caminhos distintos. Critérios de julgamento pressupõem exclusão, enquanto avaliação pressupõe acolhimento.

Defino a avaliação da aprendizagem como um ato amoroso, no sentido de que a avaliação, por si, é um ato acolhedor, integrativo, inclusivo. Para compreender isso, importa distinguir avaliação de julgamento. O julgamento é um ato que distingue o certo do errado, incluindo o primeiro e excluindo o segundo. A avaliação tem por base acolher uma situação, para, então (e só então), ajuizar a sua qualidade, tendo em vista dar-lhe suporte de mudança, se necessário. (LUCKESI, 1999, p. 172).

Auxiliar no processo de ensino-aprendizagem, a avaliação escolar mantém estreitas relações com a avaliação em cursos superiores. Nas licenciaturas desempenha um importante papel na formação do futuro docente e em cursos de artes adquire especificidades que serão tratadas na sequência deste texto. Antes de explicitar tais singularidades, contudo, serão esclarecidas algumas questões acerca de processos avaliativos na Educação Superior.

\section{Educação superior: em busca da compreensão humanista}

No que tange aos cursos superiores, busca-se incentivar os alunos a adquirir uma competente formação profissional que inclua questões humanistas e éticas, despertando a curiosidade acerca de novas alternativas, sejam elas práticas ou teóricas. Cabe ao educador estar aberto às dúvidas, promovendo o diálogo com os estudantes e dando apoio por ocasião do enfrentamento de dificuldades. Com o objetivo de criar situações que propiciem o desenvolvimento do futuro profissional, Marcos Masetto destaca que é importante levar em conta o desenvolvimento afetivo-emocional, a aquisição de valores e o comprometimento com as atitudes. Segundo ele: 
Superando a formação voltada apenas para o aspecto cognitivo, o que se busca é que o aluno em seus cursos superiores desenvolva competências e habilidades que se esperam de um profissional capaz e de um cidadão responsável pelo desenvolvimento de sua comunidade. (MASETTO, 2012, p. 24).

$\mathrm{O}$ comprometimento com os processos de ensino, com o incentivo à pesquisa e com a parceria aluno/ professor são alguns dos elementos fundamentais para que as transformações no ensino, na aprendizagem e nos processos de avaliação se adéquem às novas gerações. Voltada para incrementar a comunidade de atuação do futuro profissional, a educação necessita desenvolver também questões éticas, preocupadas com a qualidade das relações humanas.

A avaliação, realizada de modo gradativo e processual, deve ser capaz de incentivar o estudante ao estudo aprofundado das questões curriculares, cuja relação com a comunidade deve ser evidente. Coadunar a experiência concreta do mundo e o legado teórico da área faz com que seja possível vislumbrar novas formas de equilíbrio dinâmico. A inter-relação de ensino, pesquisa e extensão, quando adotada como critério de fundamentação da avaliação, parece ser uma maneira menos equivocada de se atribuir valor aos processos de ensino e aprendizagem.

As possibilidades abertas por novas práticas avaliativas, como se pode deduzir da afirmação acima, indicam que a grade curricular, os planos de ensino e outras instâncias da educação superior, elementos estreitamente relacionados à avaliação, também carecem de revisão. De um modo simplificado, pode-se afirmar que, quando a ênfase da educação é colocada na aprendizagem e não no ensino, subvertem-se muitas práticas tradicionais, dentre as quais a hegemônica forma de avaliação, cujo modelo é pautado na valoração de um produto final, o qual, em significativa parte das vezes, é o resultado de respostas às indagações organizadas pelo professor e não necessariamente adequadas aos estudantes.

Para uma análise dos processos de avaliação no ensino superior, deve-se levar em conta que o caminho do docente é, muitas vezes, construído nos cursos de formação e, por mais que estes cursos sejam bons, não garantem a formação das habilidades e competências necessárias para o encontro de soluções pedagógicas acerca dos problemas de ensino e aprendizagem enfrentados na profissão.

Espécie de indicativo da qualidade do resultado obtido, o processo de avaliação deve ser complementado pela gestão do curso, cuja finalidade é possibilitar, de forma prática, o aprimoramento educacional. Tratada sob um aspecto mais amplo, para além da aprendizagem do estudante, a avaliação é necessária para todo o sistema da educação e, de modo específico, serve para uma melhor compreensão do que acontece na sala de aula e no curso. Diagnóstico das ações produzidas, sinaliza se os professores atingiram ou não a qualidade almejada. 
De acordo com Vieira e De Sordi (2012), pesquisadoras que adotam o Portfólio como critério organizador da avaliação, a capacidade de atribuir valor é um dos elementos fundamentais da prática pedagógica, pois possibilita o aprimoramento dos processos de ensino e aprendizagem, explicitando os objetivos atingidos e identificando aquilo que ainda precisa ser trabalhado. Ao revelar a qualidade da realidade do aprendizado, a avaliação se volta, portanto, para um redimensionamento da atuação do professor, para quem o equivalente do ensinar é o aprender.

Tendo em vista que o compromisso da docência no ensino superior vai além da reprodução dos conhecimentos existentes na área, ao produzir conhecimento básico para diversas instâncias da educação, a avaliação necessita do rigor metodológico que caracteriza o ensino universitário, para não incorrer no risco de se perder em excessos de subjetividade e critérios emocionais. Os processos avaliativos, contudo, tratam também de assegurar o desenvolvimento do pensamento crítico e criativo, na busca de respostas para as substanciais alterações sociais e educacionais que se apresentam na atualidade.

Alguns cuidados devem ser tomados ao realizar uma avaliação, e mesmo que tais critérios possam parecer evidentes, é importante lembrar que seu caráter processual deve ser destacado e que se deve ter por objetivo a promoção da inclusão, a valorização da autonomia, e a capacidade de promover o diálogo e as reflexões coletivas. Ao buscar respostas e caminhos para os problemas identificados, o processo de avaliação não pode ser punitivo nem estigmatizante, ao contrário, deve possibilitar o encontro de diretrizes para a definição de prioridades e tomada de decisões (MITRE et al., 2008).

A avaliação pode identificar singularidades em processos de produção e instigar à iniciação científica, espaço aberto para graduandos em pesquisas acadêmicas. Como em grande parte das avaliações, deve se destacar, por parte do professor, o conhecimento atualizado do conteúdo, no que concerne ao repertório prático e teórico, fator que o habilita a apontar qualidades e problemas nos trabalhos desenvolvidos.

O desenvolvimento de um pensamento criativo e reflexivo é uma das tarefas a que o ensino superior se propõe. De acordo com Joe Garcia, para que isto aconteça é necessária uma nova arquitetura curricular, com novos conteúdos e competências, repensando os processos de ensino e aprendizagem, dentre os quais destaca as práticas avaliadoras. Ao colocar em pauta os critérios para valoração do trabalho dos estudantes, ele enfatiza: 
Essa escolha precisa levar em conta tanto o tipo de aprendizagem que queremos adotar quanto as possíveis respostas dos alunos a ela. Diversas pesquisas sugerem que, mesmo conhecendo muito sobre as características e formas de aplicação de diversos métodos de avaliação na educação superior, ainda não sabemos o suficiente a respeito de como conseguir, de maneira sistemática, que os estudantes experimentem determinadas formas de aprendizagem (GARCIA, 2009, p. 212).

Para Garcia, o caráter formativo das experiências avaliativas repercute no planejamento do tempo de estudo, definindo prioridades para a execução de tarefas acadêmicas. Ao destacar a importância da cultura avaliativa nos cursos superiores, ele lembra que as práticas de avaliação costumam se pautar em poucas escolhas, dentre as quais destaca a "avaliação somativa", a qual, ao manter um modelo antigo da cultura da educação, pode ter seu valor questionado na atualidade.

O que se percebe, é que alguns cursos superiores, especialmente os ministrados nas ciências exatas, permitem uma grande objetividade nas avaliações; outros, ligados às ciências humanas, requerem uma maior parcela de subjetividade na análise dos trabalhos apresentados. Questões ligadas à estética ou à poética complexificam, sobremaneira, os critérios de avaliação. As dificuldades que envolvem as avaliações nos cursos superiores de artes se ampliam em função da abordagem individual e específica que deve ser levada em conta ao se atribuir critérios de valor ao processo de trabalho do estudante, cujas pesquisas costumam percorrer trajetos permeados por constantes incertezas. Buscar-se-á identificar algumas das peculiaridades da avaliação em artes no tópico a seguir.

\section{Cursos de artes: o equilíbrio entre subjetividade e objetividade na avaliação}

Os cursos de Artes, na Educação Superior, requerem, por parte do professor, um comprometimento com a efetiva elucidação dos critérios adotados na avaliação, conteúdo indispensável, especialmente, quando se trata de cursos de licenciatura. Preparar os novos professores para atuar no ensino fundamental faz com que, dentre as habilidades desenvolvidas pelos estudantes universitários, deva constar a capacidade de dialogar sobre arte e tecer reflexões sobre a produção realizada em ateliês. O objetivo da avaliação é apontar caminhos para o desenvolvimento do trabalho do jovem artista e isto pode acontecer através da indicação de referenciais teóricos e imagéticos, como também da detalhada análise da obra realizada.

O caráter subjetivo de tal tipo de avaliação não pode ser ignorado e por mais que se procure traduzir questões sensíveis de modo racional, as particularidades de uma avaliação em cursos de artes são permeadas pelo repertório do grupo de professores e de suas respectivas capacidades de trabalhar com o campo do sensível. Uma educação pelo sensível, a qual deveria 
permear todas as instâncias educacionais, mas que se destaca nas ciências humanas revela, acima de tudo, a preocupação com os destinos da sensibilidade dos educandos.

Desenvolver o senso crítico a respeito de práticas avaliativas no ensino superior implica ter em mente que "o processo de produção e distribuição de conhecimento jamais foi o intercâmbio livre, objetivo e puramente intelectual que os racionalistas disseram ser" (FEYERABEND, 2011, p. 171). Ao abordar questões acerca do caráter científico da educação e destacar os perigos de um pensamento que visa estabelecer uma única verdade, o filósofo esclarece:

Uma sociedade que é baseada em um conjunto de regras restritivas e bem definidas, de forma que o ser humano torna-se sinônimo de obedecer essas regras, força o dissidente a uma terra de ninguém sem regra nenhuma e despoja-o assim de sua razão e de sua humanidade. (FEYERABEND, 2011, p. 213).

Ao destacar a arbitrariedade dos instrumentos de medição e de avaliação que permeiam as diversas culturas, Feyerabend pontua que a ênfase nas tecnologias, em detrimento de uma relação harmônica com a natureza, faz com que as informações quantitativas e teóricas sejam consideradas reais, enquanto as questões qualitativas passam a ser consideradas secundárias ou aparentes. Ao propor uma espécie de procedimento anárquico em relação à metodologia de pesquisa científica e questionar aspectos basilares dos modos investigativos tradicionais, seu legado parece arejar, de maneira inigualável, a produção de arte e sua subsequente avaliação.

De acordo com Irene Tourinho, a avaliação é um processo pautado no entrelaçamento de decisões racionais e afetivas. Para ela, o bom planejamento de ensino não garante a qualidade do aprendizado e as dificuldades para se estabelecer objetivos claros nas avaliações não podem ser escamoteadas. Uma das singularidades da avaliação em arte é ser atração gerada pela provocação (TOURINHO, 2010). Ao tecer uma analogia com a imagem de uma bala, explicita as dificuldades da avaliação no ensino da Arte:

\footnotetext{
Seríamos um ensino-bala: enrolado nas duas pontas, antes de ser aberta para desfrute. Numa ponta estamos "enrolados" pela complicação e necessidade de pertencer, dignamente, à organização que os campos de conhecimento assumem na escola (disciplinas?; projetos?; temas?...). Na outra, também estamos "enrolados" pela ausência de parâmetros que fundamentem a avaliação, necessária para o ensino, para alunos e para nós, professores. (TOURINHO, 2002, p. 34).
}

A interlocução com arte-educadores, visando explicitar caminhos da avaliação, tem por objetivo fomentar um campo espinhoso, cujos estudos são fundamentais para a prática pedagógica. Avaliar atividades desenvolvidas em ateliês de arte na Educação Superior implica incorporar o erro, expor-se a riscos e pensar na convivência entre os estudantes. Tal tarefa, a de ministrar aulas práticas em ateliês, costuma ser desenvolvida por um artista que opta por se tornar também professor. 
O artista-professor é um produtor de arte que mantém estreitos vínculos com o ensino e a pesquisa. De acordo com Célia Maria de Castro Almeida, a presença do artista-professor nas universidades brasileiras potencializa a interlocução entre os interessados em determinada área, afastando o professor da solidão que envolve o trabalho artístico e possibilitando que o mesmo desenvolva sua pesquisa sem a necessidade de ceder às mudanças constantes que envolvem o universo das galerias e da comercialização da arte.

O artista-professor não fala de um fazer de maneira teórica, abstrata; fala de um trabalho concreto que ele conhece a fundo. Por outro lado, esse falar é profícuo para o fazer concreto. Porém, há um ir e vir constante que enriquece o trabalho docente e o fazer artístico. (ALMEIDA, 2009, pos. 1387).

O artista-professor, ao adotar o ensino superior como lócus de suas pesquisas, de certa forma compartilha e amplia o escopo de suas investigações, colocando-se disponível para questionamentos e discussões sobre a produção de arte na universidade e sua inserção no mercado de trabalho. O professor de arte, distintamente do artista-professor, e sem que isso implique critérios de valor, não necessariamente desenvolve uma produção artística, dedicandose a estudos teóricos sobre arte, tais como questões acerca da educação pelo sensível e os fundamentos teóricos da arte.

\section{Considerações finais: a complexidade dos critérios de avaliação}

A problemática da avaliação é tema de constantes debates, os quais apontam problemas sem conseguir chegar a conclusões definitivas. Seus estudos implicam a revisão de conceitos e apontam para o constante aprimoramento do professor em relação às pesquisas do campo. $\mathrm{Na}$ ausência de um modelo ideal ou totalmente satisfatório, cabe ao professor o encontro de alternativas com vistas a uma atitude acolhedora, inclusiva e formativa, cujo objetivo é a formação integral do estudante.

$\mathrm{Na}$ Educação Superior presencia-se um aumento da complexidade nos processos avaliativos, em função da amplitude aberta pelas pesquisas docentes e discentes. Considera-se fundamental, não apenas preparar o estudante para o mercado de trabalho, mas também promover a formação profissional capaz de atuar eticamente nas sociedades que se encontram em constantes transformações. Reflexão, crítica e autocrítica são modelos didáticos imprescindíveis para o aprimoramento de educação, que se colocam no lugar das práticas avaliativas autoritárias.

Os cursos universitários de artes, caracterizados pelas tentativas de equilíbrio dinâmico entre objetividade e subjetividade, são permeados pela complexidade nos critérios de avaliação. A análise dos trabalhos produzidos nos ateliês implica a correlação com o mercado de arte 
contemporânea, cuja atualidade não pode passar despercebida, nem pelos estudantes, tampouco pelos professores. Ao propor, nas avaliações, a correlação com a concretude do mundo do trabalho, emergem critérios cujo objetivo é promover a autonomia do estudante rumo à atuação profissional.

Nesta perspectiva, que valoriza tanto o processo quanto o produto, buscou-se apontar, para além do valor da obra produzida, caminhos que conduzam à conscientização de que a produção de arte requer a pesquisa contínua, a superação dos conhecimentos anteriormente conquistados e a coragem de adentrar no campo do desconhecido. Se as dificuldades de se estabelecer o que é arte assolam as discussões sociais, é inevitável que tais questões repercutam nas disciplinas de ateliês, lócus para tal tipo de embate.

\section{Referências}

ALMEIDA, Célia Maria de Castro. Ser artista, ser professor: razões e paixões do ofício. São Paulo: UNESP, 2009.

FEYERABEND, Paul. Contra o método. 2. ed. São Paulo: UNESP, 2011.

GARCIA, Joe. Avaliação e aprendizagem na educação superior. Estudos em Avaliação Educacional, São Paulo, v. 20, n. 43, p. 201-213, maio/ago. 2009.

LIBÂNEO, José Carlos. Didática. São Paulo: Cortez. 2006.

LUCKESI, Cipriano Carlos. Avaliação da aprendizagem escolar: estudos e proposições. 9. ed. São Paulo: Cortez, 1999.

MASETTO, Marcos Tarciso. Competência pedagógica do professor universitário. 2. ed. São Paulo: Summus, 2012.

MITRE, Sandra Minardi et al. Metodologias ativas de ensino-aprendizagem na formação profissional em saúde: debates atuais. Revista Ciência \& Saúde Coletiva, Rio de Janeiro, v. 13, n. 2, p. 2133-2144, 2008.

MORIN, EDGAR. Os sete saberes necessários para a educação do futuro. Tradução: Catarina Eleonora F. da silva e Jeanne Sawaya. 2 ed. São Paulo: Cortez: UNESCO, 2011.

READ, Herbert. A Educação pela Arte. 2. ed. São Paulo: Martins Fontes, 2013.

TOURINHO, Irene. Transformações no ensino da arte: algumas questões para uma reflexão conjunta. In: BARBOSA, Ana Mae (org.). Inquietações e mudanças no ensino da arte. São Paulo: Cortez, 2002. p. 28-36.

TOURINHO, Irene. Retomando um tema delicado: avaliação e ensino de arte. In: ENCONTRO DA ASSOCIAÇÃO NACIONAL DE PESQUISADORES EM ARTES 
PLÁSTICAS - ANPAP, 19., 2010. Cachoeira. Anais.... Salvador: EDUFBA, 2010. p. 20942106.

VIEIRA, Maria Lourdes; De SORDI, Mara Regina Lemes. Possibilidades e limites do uso do Portfólio no trabalho pedagógico no ensino superior. Revista E-curriculum, São Paulo, v. 8, n. 1, p. 1-27, abr. 2012. 